plasma active renin levels after standing. A short Synacthen test showed a normal cortisol response (baseline cortisol level was $235 \mathrm{nmol} / 1$, cortisol level one hour after $250 \mu \mathrm{g}$ of Synacthen was $734 \mathrm{nmol} / \mathrm{l}$.

A permanent 'on-demand' cardiac pacemaker was inserted and oral calcium resonium and a low potassium diet was continued. After 2 months, hypokalaemia (potassium level $2.8 \mathrm{mmol} / \mathrm{l}$ ) developed and the calcium resonium and low potassium diet were stopped. On further follow-up he remains well although a tendency to hyperkalaemia persists (potassium levels $=5.0-5.1$ $\mathrm{mmol} / \mathrm{l}$; reference range $=3.4-5.0 \mathrm{mmol} / \mathrm{l}$ ).

Ibuprofen may have been implicated in the cardiac dysrhythmias, by provoking hyporeninaemic hypoaldosteronism in a patient with underlying autonomic dysfunction. We have not rechallenged the patient to ibuprofen. The resulting hyperkalaemia in our patient led to life-threatening dysrhythmias which required intracardiac pacing. Our case also demonstrates that regular follow-up of potassium levels is necessary because the hyporeninaemic hypoaldosteronism caused by nonsteroidal anti-inflammatory drugs can be reversible, and continued calcium resonium therapy may lead to hypokalaemia.

\section{T. Masud \\ P. Winocour \\ F. Clarke \\ Freeman Hospital, \\ High Heaton, \\ Newcastle-Upon-Tyne NE7 7DN, UK.}

\section{References}

1. Seaton, P.E. \& Biglieri, E. Reduction in aldosterone excretion in patients with autonomic insufficiency. $J$ Clin Endocrin Metab 1975, 41: 611-617.

2. Tan, S.Y., Shapiro, R., Franco, R. et al. Indomethacin induced prostaglandin inhibition with hyperkalaemia. A reversible cause of hyporeninaemic hypoaldosteronism. Ann Intern Med 1979, 90: 783-785.

3. Ewing, D.J. \& Clarke, B.F. Diagnosis and management of diabetic autonomic neuropathy. $\mathrm{Br}$ Med J 1982, 285: 916-918.

4. Smith, S.A. \& Dewhurst, R.R. A simple diagnostic test for pupillary abnormality in diabetic autonomic neuropathy. Diabetic Med 1986, 3: 38-41.

\section{Carcinoma of the pancreas in a young male}

Sir,

Carcinoma of the pancreas is a disease of the elderly and is rare in younger age groups. We report a 22 year old male, the youngest patient to our knowledge with carcinoma of the pancreas with associated chronic calcific pancreatitis.

A 22 year old male farm worker from North India presented with constant pain in the epigastrium radiating to the back of 6 months duration and progressive cholestatic jaundice of 2 weeks duration. He had anorexia and significant weight loss. He was found to have diabetes 5 years ago and was on insulin therapy. On examination he was icteric and had a tender, firm well-localized mass in the epigastrium and a smooth, non-tender gallbladder lump. Investigations revealed haemoglobin of $10.4 \mathrm{~g} / \mathrm{dl}$ total leukocytic count of $21 \times 10^{9} / 1$ with $88 \%$ poly- morphs, serum bilirubin $167 \mu \mathrm{mol} / \mathrm{l}$, serum alkaline phosphatase $607 \mathrm{IU} / \mathrm{l}(n=35-125)$, transaminases 108 / $261 \mathrm{U} / 1(n=5-40)$ and serum amylase $24 \mathrm{U} / 1(n=30-$ $110)$. Plain $X$-ray of the abdomen revealed speckled calcification at $\mathrm{L} 1-2$ level. Ultrasonography and computed tomographic scan of the abdomen revealed dilated intrahepatic biliary radicles and a distended gallbladder; the common bile duct measured $16 \mathrm{~mm}$ in width. Calcification was seen in the pancreatic tissue and a hypoechoic mass was seen in the head of the pancreas. The pancreatic duct measured $8.6 \mathrm{~mm}$ and had calculi in it. Ultrasound-guided fine needle aspiration biopsy revealed features suggestive of malignancy.

At laparotomy, there was a $8 \times 9 \mathrm{~cm}$ hard mass in the head of pancreas extending across into the neck. Vascular planes posterior and inferior to the pancreas were obliterated. Cholecystojejunostomy, gastrojejunostomy and chemical coeliac plexus block was performed. Histopathology of the intraoperative trucut needle biopsy from the mass revealed a poorly differentiated adenocarcinoma. Postoperatively, his jaundice regressed and he was relieved of pain. The final diagnosis was chronic calcific pancreatitis with carcinoma of the pancreas and diabetes mellitis.

Carcinoma of the pancreas is usually seen in the sixth and seventh decades. In 1990 Hena et al. reported a 28 year old female as the youngest case of carcinoma of the pancreas in the English language literature. ${ }^{1}$ To the best of our information, our patient appears to be the youngest patient reported to have carcinoma of the pancreas.

Carcinoma of the pancreas is more frequent in population with chronic pancreatitis. ${ }^{2}$ The incidence of carcinoma of the pancreas in association with chronic pancreatitis is variable. In a study of 240 patients with tropical pancreatitis, $22(9.4 \%)$ developed carcinoma over a follow-up period of 7 years. ${ }^{3}$ Malignancy as a sequel of chronic pancreatitis has not been established but the association between the two conditions is well documented. $^{4}$

Prognosis of patients with carcinoma of the pancreas in association with chronic pancreatitis is dismal as the diagnosis is frequently delayed. Mean survival of these patients after diagnosis is $2-3.5$ months. ${ }^{2,3}$

Wasif Ali
S.S. Sikora
S.P. Kaushik
Department of Surgical Gastroenterology,
Sanjay Gandhi Postgraduate Institute of
Medical Sciences,
Lucknow 226001,
India.

References

1. Hena, M.A., Gonssovs, H.G. \& Newkirk, R.E. Pancreatic cancer in a young adult. Am $J$ Gastroenterol 1990, 85: $102-103$

2. Haas, O., Guillard, G., Rat, P., Freidman, S. \& Favre, J.P. Pancreatic cancer developing in chronic pancreatitis - a report of 4 cases. Hepatogastroenterology 1990, 37: 350-351.

3. Shenoy, K.T., Narendranathan, M. \& Hariharan, M. Tropical pancreatitis - sequelae and complications - a prospective study. In: Balakrishnan, V. \& Thankappan, K.R. (eds) Proceedings of the Annual Conference of the Indian Society of Pancreatology. Trivandrum Medical College, Trivandrum, 1986. 
4. Thomas, P.G., Augustine, P., Ramesh, H. et al. Observations and surgical management of tropical pancreatitis in Kerala and Southern India. World J Surg 1990, 14: 32-42.

\section{Measurement of visual acuity by hospital physicians}

Sir,

Ophthalmological disease is an important cause of morbidity in general practice and hospital in-patients. Assessment of visual health is therefore a vital part of patient care. It is particularly important when referring a patient with visual problems to an ophthalmologist that an assessment of visual acuity is included in the referral letter. ${ }^{\prime}$ This aids the ophthalmologist in deciding the degree of urgency with which a patient needs to be seen.

We report the results of a study carried out to assess whether hospital physicians were able to measure visual acuity and accurately record this information. A group of hospital physicians was randomly selected from four hospitals in the West Midlands region. The ability to assess visual acuity was determined using a standard four-part questionnaire:

1. What is the name of the chart used to assess distance visual acuity?

2. What is the usual correct distance between the chart and the patient?

3. If the patient usually wears spectacles, but has forgotten them, how can you get a rough assessment of their corrected visual acuity?

4. How would you record the visual acuity of this patient's right eye? (Shown a Snellen chart with patient able to read line indicated).
One hundred and two doctors of all grades were questioned. Only $25(24.5 \%)$ doctors questioned were able to answer all four questions correctly. Ninety-five $(93 \%)$ answered question 1 correctly but the correct response rates were $70 \%, 56 \%$ and $63 \%$ for questions 2,3 and 4 , respectively.

It is clear from these results that, although most doctors in our study group know the name of the chart used to measure distance visual acuity, many are not familiar with the practicalities of actually measuring visual acuity using it. Only $60 \%$ of doctors questioned who were of registrar level or below could accurately measure and document a patient's visual acuity so that the information would be of value to an ophthalmologist reading a referral letter. Another finding to emerge from this study was that Snellen charts were only generally available in accident and emergency departments, ophthalmology clinics and diabetic clinics/wards.

We feel that it is important that adequate time is allocated to the study of ophthalmology in the undergraduate curriculum so that all doctors can learn the basic examination skills necessary to assess ophthalmic problems.

\section{P. Shah \\ S.J. Talks \\ F. Pochkhanawala Department of Ophthalmology, Birmingham and Midland Eye Hospital, Church Street, Birmingham, $U K$.}

\section{Reference}

1. Sheldrisk, J.H., Vernon, S.A. \& Wilson, A. Study of diagnostic accord between general practitioners and an ophthalmologist. Br Med J 1992, 304: 1096-1098.

\title{
FELLOWSHIP OF POSTGRADUATE MEDICINE
}

\author{
Grants for Research - 1993
}

The Fellowship of Postgraduate Medicine is offering grants for travel, or towards the cost of equipment, for young graduates entering careers in clinical research. Successful applicants will be expected to submit reports of their research for publication in the Postgraduate Medical Journal.

Further information may be obtained from Mrs J.M. Coops, Fellowship of Postgraduate Medicine, $6 \mathrm{St}$ Andrew's Place, London NW1 4LB (Tel: 071-935 5556), to whom applications should be made, giving a concise summary of the research project, the sum requested and a curriculum vitae of the applicant. 